\title{
Rigid-Flexible Coupling Dynamics Simulation Analysis of Wheel/Rail Interaction in High-speed Turnout Zone
}

\author{
Miao $\mathbf{Y u}{ }^{1}$ \\ China Academy of Railway Sciences \\ Beijing, 100081, China \\ E-mail: ym8905310163.com \\ Weidong Wang \\ China Academy of Railway Sciences \\ Beijing, 100081, China \\ E-mail: drwangerails.cn \\ Jinzhao Liu ${ }^{2}$ \\ Infrastructure Inspection Research Institute, China Academy of Railway Sciences \\ Beijing, 100081, China \\ E-mail: liujinzhao@rails.cn

\section{Jianjun Qu} \\ Infrastructure Inspection Research Institute, China Academy of Railway Sciences \\ Beijing, 100081, China \\ E-mail: qujianjunerails.cn
}

\begin{abstract}
Aiming at No. 18 high-speed turnout, a dynamic model of vehicle/turnout rigid-flexible coupling system has been established to analyze wheel/rail interaction when a train passed through turnout at different speeds. By Wigner-Ville distribution based on the time-frequency analysis, the axle-box acceleration (ABA) was further studied. Bending deformation of the flexible wheelset under axle load makes a small constant amplitude vibration of the wheel/rail force and the ABA. When a train passes through a turnout in the main and diverging routes, the long nose rail width around $0.04 \mathrm{~m}$ and the curved switch rail width around $0.02 \mathrm{~m}$ receive impacts from the wheel. It leads to the vertical high frequency ABA at around $300 \mathrm{~Hz}$ which is close to the natural frequency of the wheelset and it's more likely to cause the wheelset compound vibration of symmetrical umbrella and the third order bending mode.
\end{abstract}

ISCC 2017

16-17 December, 2017

Guangzhou, China

\footnotetext{
${ }^{1}$ Speaker

${ }^{2}$ This study is supported by Scientific research plan projects of CHINA RAILWAY (2017G011-B) (2017G011-E)
} 


\section{Introduction}

It is well known that the high-speed turnout is a weakness of high-speed railway. At present, China has laid more than 5 thousand high-speed turnouts and most of them appear well. However, there are still some problems, such as the abnormal shaking of the car body caused by ultra-limit geometrical parameters, deficient displacement of switch rail and nose rail, curved switch rail wear and surface contact fatigue, bolt hole cracks and rail fastenings loosening [1].

The research on wheel/rail dynamic interaction has been studied for many years. Multibody dynamics method is used by many scholars. Schupp investigated multi-point contact in turnout with multi-body dynamics [2]. Kassa established the vehicle/turnout dynamic model to explore dynamic response under the random input of critical parameters [3]. Wang Ping conducted the multi-point wheel/rail contact relationship research in the turnout zone according to the wheel/rail system dynamics and the rail structure characteristics [4]. Ren Zunsong studied the multi-point contact and vehicle/turnout system dynamic during passing the turnout with SIMPACK [5]. In addition, the finite element method is widely available. Pletz focused on the dynamic model of a single wheel rolling through the crossing [6]. M. Wiest explored the explicit finite method to deal with nose rail wear and fatigue problems [7].

The research into the vehicle/turnout dynamic interaction has been limited to the low frequency time domain by now with the vehicle/turnout coupling dynamics theory [8]. This paper will aim at the $350 \mathrm{~km} / \mathrm{h}$ high-speed train dynamic behavior coupling with No.18 highspeed ballastless turnout. The dynamic model of the vehicle/turnout rigid-flexible coupling system will be established. The short wave impact on the high frequency vibration of the axlebox will be analyzed by Wigner-Ville distribution based on the time-frequency analysis.

\section{Dynamic Model of Vehicle/Turnout System}

\subsection{Vehicle/Turnout Coupling System Structure}

The vehicle/turnout coupling simulation includes the vehicle model, the turnout model and the wheel/rail contact model. The wheel/rail contact force $P$ is utilized to make a couple of the vehicle model and the turnout model, as shown in Fig. 1.
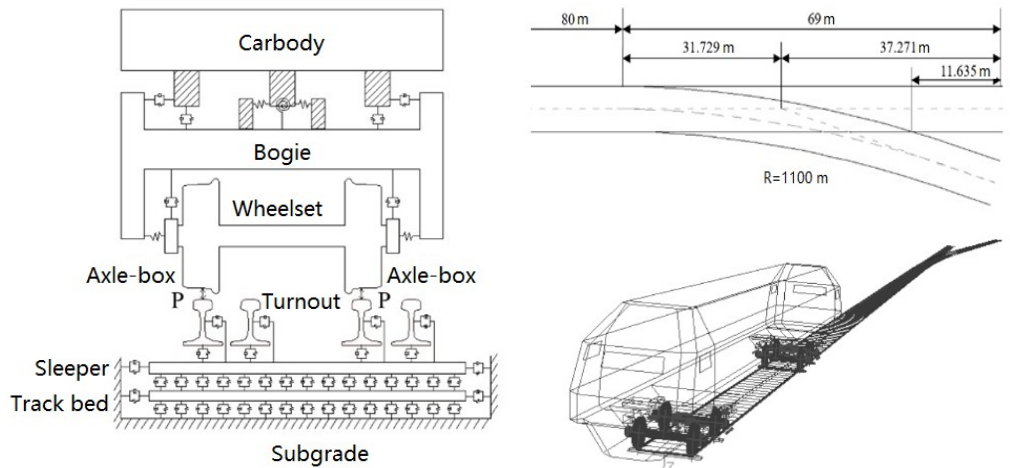

Figure 1: Vehicle/Turnout System Sructural Schematic Diagram

The dynamic model of vehicle system was built by using dynamical simulaton software of SIMPACK according to the parameters of some high-speed train in China. The vehicle model mainly consists of three parts, a car body, two frames and four wheelsets. Based on the dynamic model of vehicle system with the maximum running velocity of $350 \mathrm{~km} / \mathrm{h}$ and the parameters of high-speed ballastless turnout, the vehicle/turnout dynamic model is established. Wheel rolling 
radius of the $\mathrm{CRH}$ is $0.43 \mathrm{~m}$ with the tread profile of LMA. In order to study the high frequency vibration of axle-box caused by the short wave impact between the wheel and the rail, the wheelset is set as a flexible body. The turnout model includes a switch zone, a crossing zone and a transition zone between them. The total length of the turnout is $69 \mathrm{~m}$ with $33 \mathrm{~kg} / \mathrm{m}$ groove guard rail in the branch line. The circular curve radius of turnout is $1100 \mathrm{~m}$ without the transition curve. The variable cross-section model of the turnout is obtained by thelinear interpolation of several characteristic sections of rails in the longitudinal direction. With the width of switch rail increasing, the wheel/rail contact moves from the stock rail to the switch rail. In order to study the coupled vibration of vehicle/turnout dynamics system, vertical and lateral stiffness and damping of turnout system were taken into account.

\subsection{Vehicle System Model}

In order to verify the correctness of the vehicle simulation model, the measured track geometric irregularity was selected in the time domain as track excitation and its amplitude fluctuation range was between -2 and $2 \mathrm{~mm}$. It includes track alignment and vertical profile irregularities of each rail. We installed a vertical acceleration sensor on the car body and measured the actual car body vibration when the high-speed train passed through the track irregularity. The simulation results of the car body vertical vibration acceleration were compared with the measured data, as shown in Fig. 2. In this paper, the positive direction of $Z$ axis points to the ground in the global coordinate system.

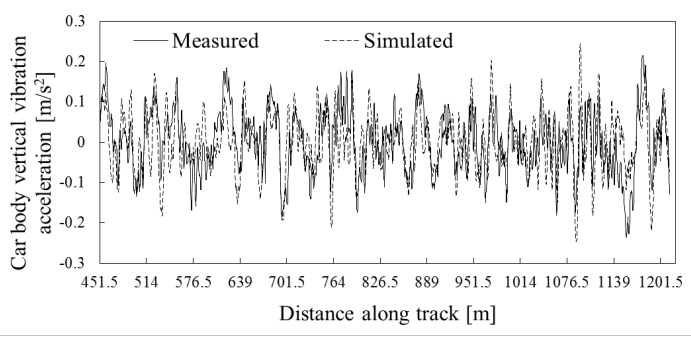

(a)

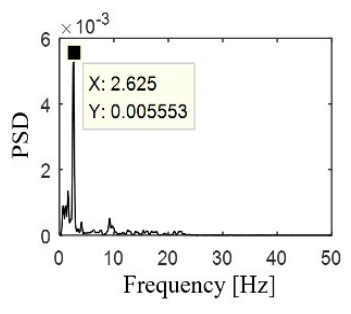

(b)

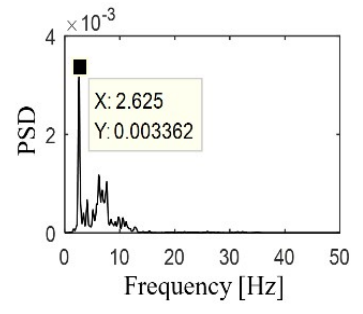

(c)

Figure 2: Car body vertical acceleration: (a) The time-domain data; (b) The frequency-domain of the measured data; (c) The frequency-domain of the simulated data.

The measured track irregularities make the changing wheel/rail contact force, which causes the vehicle system vertical vibration. The wheel/rail contact force is the input excitation of vehicle system and the car body vertical acceleration is the output response. We can validate the vehicle system model by comparing the simulated results and the measured data of the car body vertical acceleration. The simulated results agree well with the measured values in the time domain. It can be calculated that both the main frequencies of them are about $2.6 \mathrm{~Hz}$. It shows that the simulation model is almost consistent with the actual vehicle system.

\subsection{Vehicle/Turnout Rigid-Flexible Coupling System Model}

To study the effect of rigid-flexible coupling dynamics on wheel/rail interaction in highspeed turnout zone and the high frequency vibration of axle-box, the wheelset is set as a flexible body. Based on co-simulation with SIMPACK and ANSYS, the modes information of flexible wheelset was obtained by ANSYS and was imported into SIMPACK. Since no constraint is imposed on the wheelset when it is calculated by ANSYS, the first six orders are the rigid body modes of the wheelset and the corresponding natural frequency is zero. Table 1 shows the flexible wheelset vibration frequency of the other first fifteen order modes. 


\begin{tabular}{|l|l|l|}
\hline Order & Vibration frequency/ Hz & Vibration modes \\
\hline 7 & 105.478 & First order torsion \\
\hline 8 & 124.469 & First order vertical bending \\
\hline 9 & 124.469 & First order lateral bending \\
\hline 10 & 188.833 & Second order vertical bending \\
\hline 11 & 188.833 & Second order lateral bending \\
\hline 12 & 296.933 & Symmetrical umbrella \\
\hline 13 & 316.122 & Third order vertical bending \\
\hline 14 & 316.122 & Third order lateral bending \\
\hline 15 & 411.658 & Antisymmetric umbrella \\
\hline
\end{tabular}

Table 1: Vibration Frequency and Mode of Flexible Wheelset

\section{Calculation Result Analysis}

\subsection{Passing through the Mmain Line}

Since the permissible maximum speed through main line of No.18 high-speed turnout is $350 \mathrm{~km} / \mathrm{h}$ and the actual passing speed is $300 \mathrm{~km} / \mathrm{h}$, the results at different speeds are compared. The initial position of the turnout in the facing move is set as $0 \mathrm{~m}$. The nose rail top is about $53 \mathrm{~m}$ distance. When the train passes through the turnout in the main route at different speeds, the wheel/rail vertical contact force waveform and peaks are shown in Fig. 3.

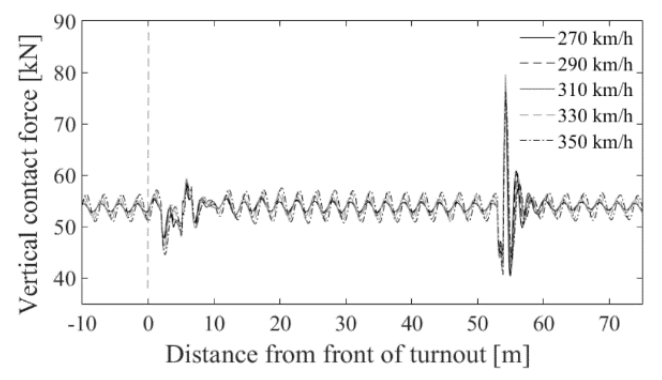

(a)

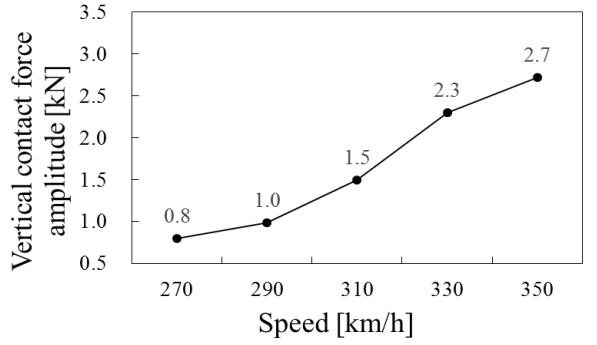

(b)

Figure 3: Wheel/rail vertical contact force: (a) Vertical contact force at different speeds; (b) Vertical contact force amplitude

In the vehicle/turnout dynamic model, the wheelset is set as a flexible body. The wheelset axle has a little bending deformation with the loads on both ends and the actual rolling radius is less than the nominal. The axle-box mass center deviates from the wheelset axle horizontal mean line. The wheel/rail vertical contact force cycles with a constant amplitude in Fig. 3. The amplitude increases slightly with the speed increasing. If the speed increases by $20 \mathrm{~km} / \mathrm{h}$, it will increase by no more than $1 \mathrm{kN}$. When the train passes through the turnout about at $7 \mathrm{~m}$ distance from the switch rail top, the switch rail width is increased from $0.02 \mathrm{~m}$ to $0.05 \mathrm{~m}$, and the wheel moves from the stock rail to the straight switch rail. The wheel/rail force descends after the rise and the difference is about $14 \mathrm{kN}$. In the crossing panel, the wheel moves from the wing rail to the long point rail at around $1 \mathrm{~m}$ from the nose rail theory top. The nose rail width is about $0.04 \mathrm{~m}$. The maximum wheel $/$ rail force is about $80 \mathrm{kN}$ which is larger than the wheel/rail static vertical contact force by 1.5 times and gives an impact on the nose rail. The ABA waveform and the peaks at different speeds are shown in Fig. 4. 


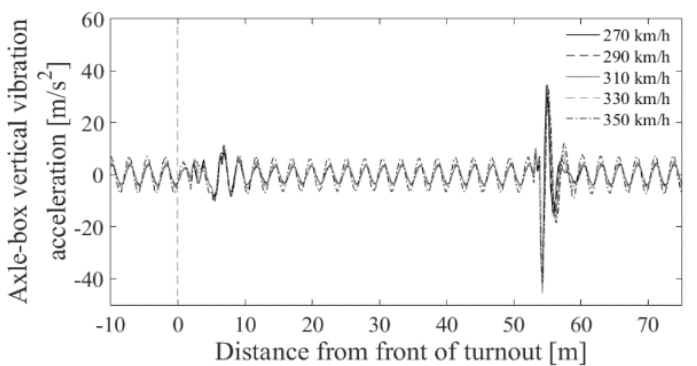

(a)
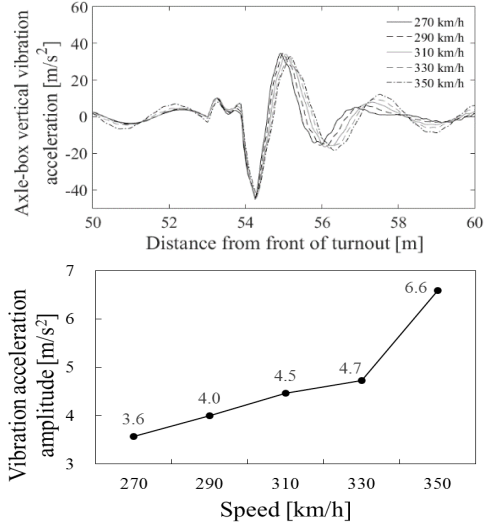

(c)

Figure 4: The ABA in main line at different speeds: (a) The ABA in main line; (b) The ABA in the crossing zone of the main line; (c) Vertical acceleration peak

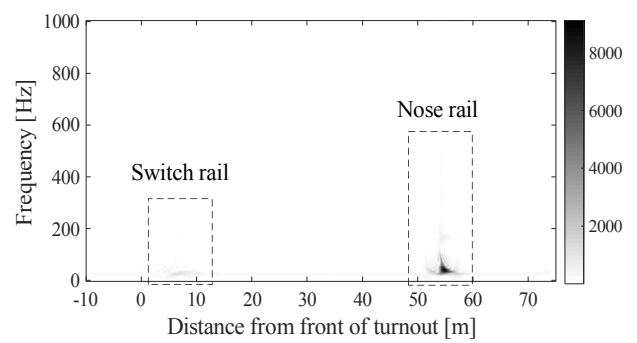

(a)

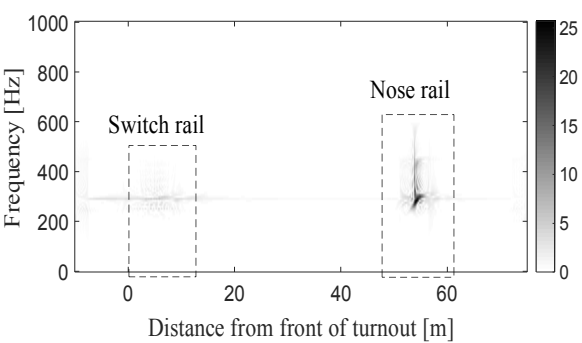

(b)

Figure 5: Time - frequency analysis of the ABA: (a) Full frequency rage; (b) In high frequency

The ABA suggests a cycle of small vibration with the amplitude of about $7 \mathrm{~m} / \mathrm{s}^{2}$ owing to axle bending. As the speed increases, the amplitude increases slightly. When the train passes a turnout through the main line, the ABA is not obvious in the switch panel. In the crossing panel, the wheelset rolls from the wing rail to the long point rail at about width $0.04 \mathrm{~m}$ and the ABA reaches the maximum value. The absolute value is about $45 \mathrm{~m} / \mathrm{s}^{2}$ which leads to an impact on the nose rail. The speeds have little effect on the values and the locations of the vertical acceleration peaks. With the increasing running speed, the vibration decay rate decreases and the wavelength increases, as shown in Figure 4(b). The ABA at $310 \mathrm{~km} / \mathrm{h}$ operating speed is selected to make further research which is close to the actual operating speed and then the time-frequency analysis is performed using the Wigner-Ville distribution, as shown in Figure 5(a). Through applying the $200 \mathrm{~Hz}$ high-pass filter to ABA, high frequency vibration results are shown in Figure 5(b).

There is a light band in the time-frequency diagram at around $30 \mathrm{~Hz}$ indicating that the dominant frequency of ABA exists throughout the whole process. Compared with the wheel rotating frequency, it can be found that the dominant frequency is derived from the flexible wheelset bending deformation. The energy of the time-frequency surface in the crossing panel is higher than that in the switch panel, when the wheel/rail contact area is changed from the wing rail to the nose rail. As shown in Fig. 5, there is a frequency of $291 \mathrm{~Hz}$ in the high frequency domain and it covers all running mileage. The impact of the nose rail stimulates the $300 \sim$ $500 \mathrm{~Hz}$ high frequency vibration of axle-box and the energy is mainly concentrated in about $300 \mathrm{~Hz}$. Compared with the vibration frequency of the flexible wheelset in the table 1, the 12th vibration frequency of the symmetrical umbrella mode is $296.933 \mathrm{~Hz}$. The 13th and 14th modes are the third order transverse and vertical bending modes with the frequency of $316.122 \mathrm{~Hz}$. The axle-box vibration frequency triggered by the impact of the wheelset at the nose rail is close to 
the wheelset natural frequency, which is easy to cause the compound vibration of the wheelset symmetrical umbrella mode and the third bending mode.

\subsection{Passing Through the Branch Line}

Since the permissible maximum speed onto siding of No. 18 high-speed turnout is $80 \mathrm{~km} / \mathrm{h}$, the simulation speed is set to as $60 \mathrm{~km} / \mathrm{h}, 70 \mathrm{~km} / \mathrm{h}, 80 \mathrm{~km} / \mathrm{h}$ and $90 \mathrm{~km} / \mathrm{h}$. While train passes the turnout through the branch line, the wheel/rail contact situation is more complicated than that in the main line. The wheel/rail contact in the switch panel from the stock rail to the curved switch rail, from the long nose rail to the short nose rail and finally through the sliding joint at the end of the short nose rail. The vertical force waveform and peaks are shown in Fig. 6.

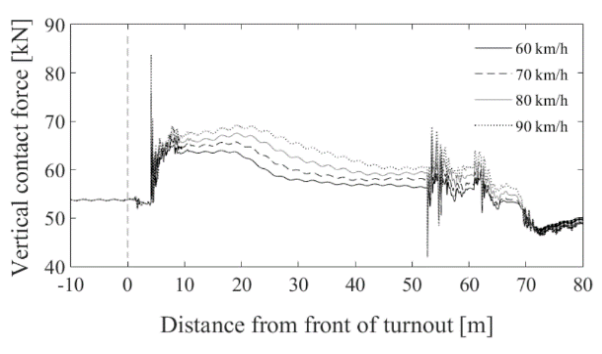

(a)

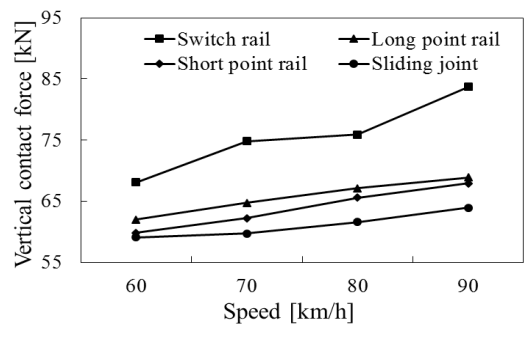

(b)

Figure 6: Wheel/rail vertical contact force: (a) Vertical contact force at different speeds; (b) Vertical contact force peak

Due to the low running speed, the vibration of the wheel/rail vertical force caused by flexible wheelset bending is not obvious. There is a circular curve with a radius of $1100 \mathrm{~m}$ in No.18 turnout branch line without transition curve. It increases wheelset attack angle on the curved switch rail at around $4 \mathrm{~m}$ position and the switch rail width is $0.02 \mathrm{~m}$. With the role of centrifugal force, the wheel/rail force in circular curve section is gradually increased. In the crossing panel, the vertical wheel/rail force presents three vibration peaks corresponding to the wheel/rail contact from the wing rail to the long nose rail, from the long nose rail to the short nose rail, and then through the sliding joints. The peak value of the vertical wheel/rail force at switch rail is larger than the others at the same speed. It is mainly due to the transition located at the initial position of the circular curve. The position where the wheel comes into contact with the switch rail is closer to the wheel flange. The top angles of the long nose rail, the short nose rail and the sliding joint gradually increase and the wheel/rail contact tends to the middle of the tread. This results that the vertical force peak decreases and the impact reduces. The ABA waveform of the train passing through turnout is almost the same at different speeds. When the train running speed is $80 \mathrm{~km} / \mathrm{h}$, the ABA is shown in Fig. 7(a), and the peaks at different speeds is shown in Fig. 7(b).

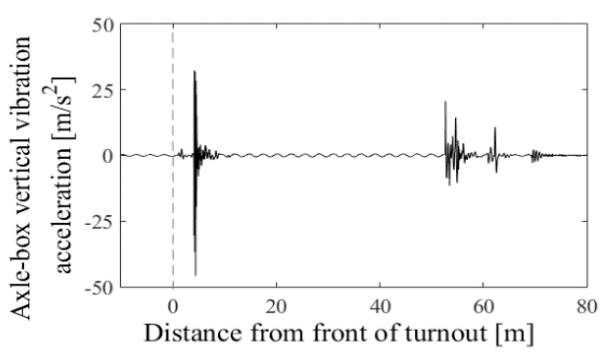

(a)

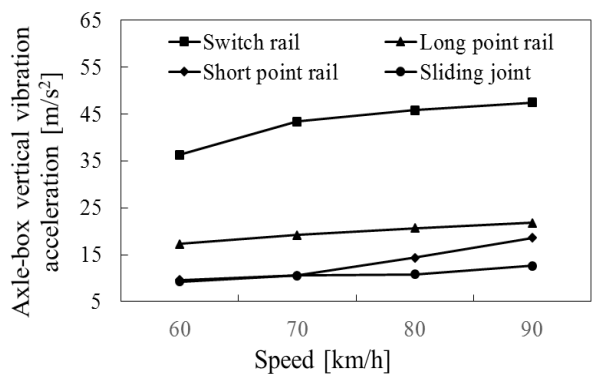

(b)

Figure 7: The ABA in the branch line: (a) At speed of $80 \mathrm{~km} / \mathrm{h}$; (b) Vertical acceleration peak 
Unlike the vertical wheel/rail force affected by the centrifugal force of the curve rail, there is not a trend item in the ABA waveform. It is easier to formulate the evaluation standard than wheel/rail force. The ABA occurs with a small cycle vibration, and the amplitude is less than $1 \mathrm{~m} / \mathrm{s}^{2}$. In the switch panel, the peak value of ABA is about $46 \mathrm{~m} / \mathrm{s}^{2}$ at about $4 \mathrm{~m}$ from the switch rail top during the transition from stock rail to the curved switch rail. In the crossing panel, three peaks of the vibration are about $0.4 \mathrm{~m}, 2 \mathrm{~m}$ and $9.5 \mathrm{~m}$ away from the point rail top with long nose rail $0.03 \mathrm{~m}$ width, short nose rail $0.02 \mathrm{~m}$ width and sliding joint $0.04 \mathrm{~m}$ width. With the speed increasing, the peak of the ABA increases gradually. At the same speed, the peak at the switch rail is larger than that at the long nose rail. The peak law is consistent with the wheel/rail vertical force. The ABA time-frequency analysis at the speed of $80 \mathrm{~km} / \mathrm{h}$ is shown in Figure 8 .

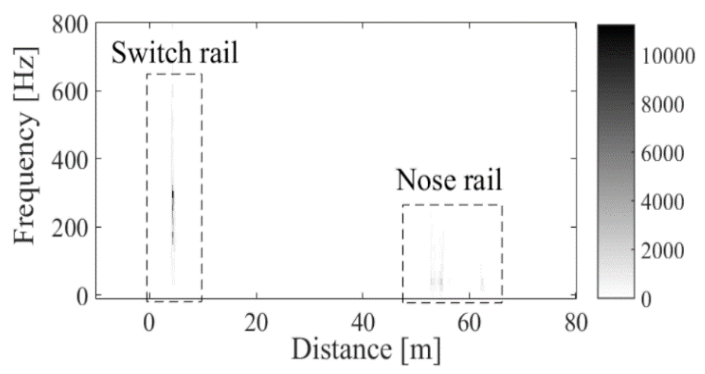

Figure 8: Time-Frequency Analysis of Vertical Acceleration

Since the running speed is low, the energy at the corresponding frequency from the flexible wheelset bending in the time-frequency diagram is not very obvious. The dominant frequency of the $\mathrm{ABA}$ is about $300 \mathrm{~Hz}$. The time-frequency surface energy is higher in switch panel than that in the crossing panel and the mileage position is about $4 \mathrm{~m}$ with the wheel/rail contact from the stock rail transition to the curved switch rail. The vibration frequency caused by the ABA corresponding to the natural frequency of the wheelset is easy to cause the wheelset compound vibration of symmetrical umbrella and third order bending mode. The impact on the crossing panel is not obvious and the time-frequency energy at the three peak positions is smaller.

\section{Conclusion}

Aiming at the $350 \mathrm{~km} / \mathrm{h}$ high-speed railway with ballastless turnout, the dynamic model of the vehicle/turnout rigid-flexible coupling system is established with the wheelsets being set up as flexible bodies. The mechanical behavior of wheel/rail contact at different speeds passing the turnout in the main and diverging routes are explored. By Wigner-Ville distribution based timefrequency analysis method are used to analyze the high frequency vibration of the axle-box when the train passes the turnout. And the following conclusions are drawn:

(1) The wheelset is set to a flexible body and the high frequency vibration of axle-box can be obtained. The bending deformation of the flexible wheelset under axle loads makes a small constant amplitude vibration of the wheel/rail force and the ABA.

(2) When train passes through the main line, the wheel/rail force in crossing panel is greater than that in the switch panel and the impact at long nose rail is about $0.04 \mathrm{~m}$ width. When train passes through the branch line, the wheel/rail force in the switch panel is greater than that in the crossing panel and the impact at curved switch rail is about $0.02 \mathrm{~m}$ width. The vertical force and the ABA are gradually increasing with the increase of the running speed.

(3) The wheel impact on the long nose rail in the main line and the curved switch rail in the branch line excite the high frequency vibration of the ABA with about $300 \mathrm{~Hz}$. It is close to 
the natural frequency of the wheelset and easy to trigger compound vibration of symmetrical umbrella and the third bending modes.

(4) The ABA can reflect wheel/rail contact state in the turnout zone and it can be used to monitor the wheel/rail contact behavior. There is less influence of the trend item from the turnout circular curve on the vibration amplitude and it is easiser to formulate the evaluation standard.

\section{References}

[1] S.G. Wang. Current Status and Future Development Trend of Railway Turnouts in China[J]. Railway Engineering. 10(1): 42-46(2015) (In Chinese)

[2] G. Schupp, C. Weidemann, and L. Mauer. Modelling the contact between wheel and rail within multibody system simulation[J]. Vehicle System Dynamics. 41(5): 349-364(2004)

[3] E. Kassa, and J. C. Nielsen. Dynamic interaction between train and railway turnout: full-scale field test and validation of simulation models[J]. Vehicle System Dynamics. 47(5): 551-574(2008)

[4] P. Wang, X.Y. Liu, and Z.H. Kou. A Study on Variation of the Vertical Rigidity of Turnout along the Longitudinal Direction of Track[J]. Journal of SouthWest JiaoTong University. 34(2):143-147(1999) (In Chinese)

[5] Z. S. Ren. Wheel/rail multi-point contacts and vehicle-turnout system dynamic interactions[M]. Science Press, Beijing. 174-228(2014) (In Chinese)

[6] M. Pletz, W. Daves, and H. Ossberger. A wheel passing a crossing nose: Dynamic analysis under high axle loads using finite element modelling[J]. Proceedings of the Institution of Mechanical Engineers, Part F: Journal of rail and rapid transit. 226(6): 603-611(2012)

[7] M. Wiest, W. Daves, F. Fischer, and H. Ossberger. Deformation and damage of a crossing nose due to wheel passages[J]. Wear. 265(9-10): 1431-1438(2008)

[8] P. Wang, R. Chen, J.M. Xu, and X.C. Ma. Theories and Engineering Practices of High-Speed Railway Turnout System: Survey and Review[J]. Journal of SouthWest JiaoTong University. 51(2): 357-372(2016) (In Chinese) 